\title{
Haven: Sharing receptive music listening to foster connections and wellbeing for people with dementia who are nearing the end of life, and those who care for them
}

\section{Claire E Garabedian}

Association for Dementia Studies, University of Worcester, Henwick Grove, Worcester, Worcestershire WR2 6AJ, UK. Email: cgarabedian40@gmail.com

Fiona Kelly

Queen Margaret University, UK

\begin{abstract}
This paper reports on research exploring the effects of music played for 12 dyads: a care home resident ('resident') with dementia and someone closely connected to him/her ('carer'). Six individualised music interventions ( 3 live and 3 pre-recorded) were played by the first author on solo cello within five Scottish non-NHS care homes. All interventions were video-recorded. Semi-structured interviews with carer participants, key staff, and managers explored their responses to interventions. Thick descriptions of video recordings and interview transcripts were thematically coded using Nvivo. A key finding was that structural elements of the interventions combined with characteristics of the music played facilitated an internalised experience of 'haven'; sonically transporting listeners away from their present reality and fulfilling the basic human needs for inclusion, comfort, identity, occupation and attachment.
\end{abstract}

\section{Keywords}

dementia, therapeutic music, end of life, communication, interaction, palliative care 


\section{Introduction}

People living in developed countries can expect to live considerably longer than in previous generations (Birch \& Draper, 2008; Hennings, Froggatt, \& Keady, 2010) and the incidence of dementia, which is predominantly a condition of older age, is also increasing (Prince, 2015). Currently there is no cure for dementia, and there are only four licensed medications available to slow down the progression of Alzheimer's disease (National Institute for Health and Care Excellence (NICE), 2018). This means that there is a growing demand for effective, nonpharmaceutical approaches for improving the lives of people with dementia (Prince, 2015).

Humans are innately social beings who rely upon social interactions in order to thrive (Hargie \& Dickson, 2006). Communication is at the core of relationship, and relationship is at the foundation of humanity (Allan, 2006; Killick \& Allan, 2001). Prior research shows that when visitors share in an activity with a care home resident, their interactions are enhanced (Froggatt, Davies, \& Meyer, 2009; Nolan et al., 2003). However, difficulties with verbal communication mean that people with dementia are often excluded from social interactions (Hubbard, Cook, Tester, \& Downs, 2002; Murphy, Gray, \& Cox, 2007), leading to isolation and depression (Hargie \& Dickson, 2006; Ward, Vass, Aggarwal, Garfield, \& Cybyk, 2008). However, music can reach people living with dementia and facilitate social connections (Gerdner \& Schoenfelder, 2010). While care homes generally provide music via group activ-ities, residents who are physically frail or have advanced dementia may not be able to attend or engage with them (Cuddy \& Duffin, 2005).

Research on the dynamic influences of music on the listener indicate that livelier music generally evokes external responses, while slower-paced music generally elicits subtler internalised responses, although the pace of music will not necessarily match its mood (Black \& Penrose-Thompson, 2012). For example, music can be slow and happy or fast and sad. 'Entrainment'; matching the rhythm of music with the pace of the listener's breath or other movements (Black \& Penrose-Thompson, 2012; Fachner, 2007; Khalfa et al., 2008) and the 'isoprinciple'; using the mood of the music to either alter or amplify the listener's mood (Bradt \& Dileo, 2010; Heiderscheit \& Madson, 2015; Hilliard, 2000), are tools com-monly used in both music therapy and therapeutic music. Alongside these physiological effects of listening to music, there are less tangible but intensely experiential feelings such as 'flow' (Csikszentmihalyi, 1997); '...[a] seamless absorption, high-level focus and .. . effort-less immersion in a pleasurable task' (Diaz, 2013, p. 43), and 'Intense Musical Experience (IME)'; where a person's'...ordinary experience and enter a world that is not comprehensible in rational terms ... . Spatial dimensions and chronological structure ceased to exist' (Sch氏fer, Smukalla, \& Oelker, 2014, p. 13).

Van der Geer, Vink, Schols, and Slaets (2009) equate the effects of music on people with dementia with that of the frequent interpersonal contact advocated within a person-centred approach to care (Kitwood, 1997). However, little is known about the potential that simply listening to music might have on improving the interactions between people living with dementia and those who are closely connected with them. Research barriers include diffi-culties with recruitment, diverse settings, co-morbidities, individual and changing musical tastes (Bradt \& Dileo, 2010), and ethical issues regarding informed consent (Calveley, 2012). The desire to amplify '... the voices of those on the social margins ...' (Hammersley \& Atkinson, 2007, p. 97) was the underlying impetus for this study.

A central premise of the Person Centred Care (PCC) model developed by Kitwood (1997) is that humans have five basic inter-related needs 
(comfort-attachment-inclusion-occupation-identity) which, when adequately addressed, fulfil our essential need for love. Brief descriptions of each of these basic needs, as they specifically pertain to people living with dementia are provided below:

\footnotetext{
Comfort: the soothing of pain and sorrow, the calming of anxiety. (Kitwood, 1997, p. 19)

Attachment: the forming of specific bonds or attachments.

Inclusion: being in or being brought into the social world, either physically or verbally. Occupation: to be involved in the process of life in a way that is personally significant. Identity: maintaining a sense of continuity with the past, and some kind of consistency across the course of one's present life. Love: to love and be loved is arguably one of the most powerful and fundamental driving forces for sustaining self-esteem and self-identity, and the need for reciprocal loving does not neces-sarily diminish with age. (Wilson, 2009, p. 84)
}

This paper reports on research (Garabedian, 2014) exploring the effect of playing personal-ised live and pre-recorded music on solo cello for 12 dyads: a care home resident living with dementia $^{1}$ estimated to be within six months of death ${ }^{2}$ as assessed using a modified version of the 'surprise question'3 (Gold Standards Framework, 2011), and a person sharing a close connection ('carer') with this resident. Following an overview of the methods used in this study, this paper discusses the key finding that the music played combined with the format of the interventions successfully fulfilled to varying degrees each of Kitwood's (1997) basic human needs - thereby engendering an internal sense of 'haven'; a place of refuge or security (English Oxford Living Dictionaries, 2018) within each participant.

\section{Methodology and methods}

The complexity of this research warranted a methodology drawn from ethnography (Hammersley \& Atkinson, 2007) and realist evaluation (Pawson, Greenhalgh, Harvey, \& Walshe, 2005; Pawson \& Tilley, 1997), and guided by the Medical Research Council's framework for evaluating complex health interventions (Craig et al., 2006).

\section{Recruitment}

Inclusion criteria for participants were: Resident - able to hear; able to speak English; have access to a private room; a formal or informal dementia diagnosis; able to provide direct informed consent; and the care home manager not being surprised if this resident were to die within the next six months (modified from the original 'surprise question' ${ }^{3}$ ). Carer - able to hear; able to speak English; have a positive connection with the resident (e.g. family, friend, or care staff); able to attend all sessions; and able to provide direct informed consent.

\section{Data collection and analysis}

In order to determine each resident's musical preferences, each carer and when possible, each resident completed an author-modified version of a musical preference questionnaire (Gerdner, 2000). Additional input was also sought from family and staff members. For some residents, an additional step involving naming and playing various pieces of usic either on the cello or via CDs in order to gauge their reactions (Clair, 2002; G6tell et al., 2009) was included. As the primary focus of the research was to facilitate engagement and connections 
within each dyad, emphasis was placed on the musical preferences of each participating resident.

Each dyad received six music interventions consisting of individualised music (3 live and 3 pre-recorded), played on the solo cello by the first author, who sat in the same location throughout all music interventions. Each intervention took place in the resident's private bedroom, and lasted between 15 and 70 minutes (depending on the resident's responses and wishes). Generally the same 'carer' was present during each intervention. Replicating the intervention format (i.e. reintroducing the study; re-establishing consent (Hubbard, Downs, \& Tester, 2003); encouraging residents to take charge of the music they were listening to) was very important.

The first authour conducted semi-structured interviews with carers and home care man-agers prior to and at the conclusion of each series of six music interventions. Questions to carers included background information, musical interests, pertinent information about their dyad partner, hopes/expectations and experiences prior to and after participating in the interventions. Questions to care home managers and key-staff included any noticable changes in each resident participant while $\mathrm{s} /$ he was particiapting in the interventions. All music interventions were video-recorded for subsequent observation by the first author; permitting her to be fully present as a practitioner/participant during each intervention, and to visit and revisit the video-footage during the months following the active fieldwork. Fieldnotes capturing the first author's observations and reflections were completed at the end of each visit.

Thick descriptions of video-observations, transcribed interviews and fieldnotes were thematically coded and managed using Nvivo 8-10. All video-footage was revisited using an authormodified version of an observation tool; 'Person Interaction Environment Care Experience in Dementia' (Brooker et al., 2011; see Garabedian, 2014). Revisiting the data helped to insure that '... respondents' voices and perspectives [were kept] alive, while at the same time recognizing the researcher's role in shaping the research process and product' (Mauthner \& Doucet, 1998, p. 119).

As inrealist evaluation (Pawson et al., 2005; Pawson \& Tilley, 1997) and ethnographic (Hammersley \& Atkinson, 2007) data analysis, a multi-dimensional approach was used to analyse the considerable amount of rich and diverse raw data collected during the fieldwork.

\section{Ethics}

Seeking to provide a voice for a particularly vulnerable population who all too often live on the social margins (Hammersley \& Atkinson, 2007), ethical approval was sought and granted from the highest level of ethical 'gatekeepers' (Dewing, 2009, p. 235) - the Scottish National Research Ethics Service (NRES). Despite underscoring the importance of including people's voices rarely heard in research and the very unlikely risk of harm and the high likelihood of benefit, regrettably, the NRES barred participation of anyone unable to provide direct informed consent; this corroborates Dewing's (2009) observation that:

\footnotetext{
'... the process researchers are expected to undertake in research submissions, particularly in relation to ethics, may limit creativity ... necessary for developing alternative consent methods where persons with dementia are excluded from informed consent.' (Dewing, 2009, p. 236)
} 
Table I. Participant characteristics and music interventions.

\begin{tabular}{|c|c|c|c|c|c|}
\hline Resident & Age & $\begin{array}{l}\text { Carer (family } \\
\text { or care staff } \\
\text { member) }\end{array}$ & Age & Relationship & \# Music interventions \\
\hline Heather & 92 & Donna (family) & 65 & Daughter & $\begin{array}{l}\text { I pre-recorded (withdrew for } \\
\text { family reasons) }\end{array}$ \\
\hline Iona & 89 & Calum (family) & 66 & Son & 3 pre-recorded $/ 3$ live \\
\hline Aileen & 93 & Tommy (family) & 61 & 3rd Cousin & 3 pre-recorded $/ 3$ live \\
\hline Bonnie & 89 & Nessa (family) & 61 & Daughter & 3 pre-recorded $/ 3$ live \\
\hline Betsie & 88 & $\begin{array}{l}\text { Gavin (family)/ } \\
\text { Morven } \\
\text { (care staff) }\end{array}$ & $\begin{array}{l}\text { 83/Early } \\
\text { thirties }\end{array}$ & Nephew/Staff & $\begin{array}{l}2 \text { live/I live \& } 3 \text { pre-recorded } \\
\text { (change of carers) }\end{array}$ \\
\hline Elspeth & 80 & $\begin{array}{l}\text { Morven } \\
\quad \text { (care staff) }\end{array}$ & Early thirties & Staff & $\begin{array}{l}2 \text { pre-recorded } / 2 \text { live (she } \\
\text { refused her final live and } \\
\text { pre-recorded } \\
\text { sessions) }\end{array}$ \\
\hline Greer & 69 & $\begin{array}{l}\text { Brenda (family/ } \\
\text { Kirsty } \\
\text { (care staff) }\end{array}$ & $\begin{array}{l}\text { Mid-thirties/ } \\
\text { mid-forties }\end{array}$ & $\begin{array}{l}\text { Daughter/ } \\
\text { Friend }\end{array}$ & $\begin{array}{l}\text { I live/l live (change of carer - } \\
\text { withdrew for } \\
\text { family reasons) }\end{array}$ \\
\hline Hazel & Mid-eighties & Sheena (care staff) & 39 & Staff & 3 live/3 pre-recorded \\
\hline Robert & 74 & Mairi (family) & 46 & Daughter & $\begin{array}{l}2 \text { live/3 pre-recorded/I live } \\
\text { (carer unable to attend } \\
\text { one session; emergency } \\
\text { live intervention) }\end{array}$ \\
\hline Edine & 92 & $\begin{array}{l}\text { Cait (family)/Bethia } \\
\quad \text { (care staff) }\end{array}$ & $\begin{array}{l}68 / \text { mid- } \\
\text { thirties }\end{array}$ & $\begin{array}{l}\text { Daughter-in-law/ } \\
\text { staff }\end{array}$ & $\begin{array}{l}3 \text { live \& } 2 \text { pre-recorded/I pre- } \\
\text { recorded (change of carer) }\end{array}$ \\
\hline Edward & 88 & Isla (family) & 59 & Daughter & 3 live $/ 3$ recorded \\
\hline Maggie & 89 & Jean (family) & 63 & Daughter & 3 pre-recorded/3 live \\
\hline
\end{tabular}

Time constraints meant that appealing this NRES decision could not be explored, there-fore only residents deemed by each care home manager to be able to provide informed consent were included in the research.

\section{Findings}

Participant characteristics and the number of music interventions are displayed in Table 1. All names are pseudonyms.

The following sections illustrate participants seemingly being 'transported' from their current realities to an internalised 'haven'; and discuss which elements likely facilitated their experience. The following sections highlight some of the primary themes (empower-ment, relaxation and enjoyment, and reconnection), as well as how specific aspects of both the intervention structure and music played contributed to these outcomes.

\section{Empowerment}

Each session began by re-introducing the study, obtaining consent for the session to commence, and handing over control of the music and session to each resident; explaining that s/he could indicate whether a tune should be replayed or skipped, the volume or tempo changed, or if the music/session should be stopped. The positive impact of residents 
experiencing even this small amount of control is shown in the excerpts below:

Recognising 'Anything goes', Bonnie begins moving her head along with the music. When the tune finished:

Bonnie: What's that you've been playin?

Author: Anything Goes. [Bonnie makes a face] Want me to play that one again?

[Bonnie smiles and nods]: I think so. Anything Goes.

Upon replaying this tune, Bonnie nods her head and sings the words during each refrain; seeming to enjoy this tune all the more for having her request acted upon.

When asked if Elspeth wished to be taken to the communal area at the apparent con-clusion of the first live-music intervention, she replied:

Elspeth: I don't think so ... I want another sing-song.

Author: [laughing] You want another song?

Elspeth: Well we might as well just sit and sing and play a song.

Apparently, Elspeth was feeling rejuvenated, and also comfortable enough to request more music; which the first author promptly delivered. Respecting Elspeth's refusal of her third prerecorded music and sixth live-music interventions supported the importance of respect-ing participants' (particularly those living with dementia) freedom to refuse any offered activity (Bartlett \& O’Connor, 2007; Hogan, 2003; Martin \& Younger, 2000).

\section{Relaxation and enjoyment}

Some carers experienced these interventions as a pleasant break from otherwise busy lives:

Donna: The music sessions gave me a break and a chance to make conversation because otherwise it's hard work with her [ - Heather].

Tommy: ... it was ... quite an enjoyable ... um ... quiet half hour or so: a brief oasis of calm in a normally busy day ...

Other carers spoke of deriving joy at seeing their dyad partner's enjoyment:

Jean: I like to see Mum [Maggie] enjoying it ... . it's brilliant. It's nice to see her getting involved in it really.

Sheena: You know and as I say Hazel's enjoyed it and that's good to watch and you know, her facial expressions and seeing that she is enjoying it.

The excerpts above show the positive impact most carers experienced when sharing a series of similarly structured interventions with their friend/family member. However, several carers spoke of experiencing tension during sessions due to feeling compelled to focus on their partner's responses. 


\section{Reconnecting}

Initial interviews found carers echoing findings from previous studies (Clair, 2002; Hughes, 2013) about the difficulties they experienced in connecting with their resident dyad partner, which often resulted in them visiting less frequently:

'... when [I] just come to visit Robert he doesn't say very much ...' (Mairi - daughter)

'... a visit to Aileen is fairly.. . well I won't say it's fairly structured but it's about the family and what I've been doing and what she's been doing and what she's been eating and what's been happening and everything's fine and then I smile and I go away .. .' (Tommy - cousin)

At the end of their series of interventions, Tommy observed: 'Whether it was the music or whether it was [Aileen] seeing me on a more regular basis ... yes, I think possibly she seemed a little ... at times I think she even joked, she smiled a little bit more than usual'. Aileen's keyworker later remarked that Tommy continued making regular visits to Aileen, and was taking greater interest in her wellbeing since the end of their interventions.

'I think just connecting with [Edward] is good because I find it very difficult to connect with him now. I mean he's obviously pleased to see me when I come in, but because he's been here nearly five years now ... it's difficult to know how to connect with him, and I would like to be able to do something with him which is more meaningful and has some purpose and which would benefit him .. . but l'm not sure what to do with him.' (Isla - daughter)

Residents and carers benefited from sharing these music interventions as sharing the experience of listening to music in a safe and comfortable environment ('haven') facilitated reconnections, which generally led to more frequent, longer visits.

\section{Music characteristics}

The tempo or speed, mood, genre, and personal significance of each piece of music played contributed to each participant's experience.

For example, after a few moments of listening to a slow-paced sad tune, Aileen inter-rupted, saying: 'I like more cheerful music - that's sad, that'. Upon the music becoming more upbeat, Aileen immediately remarked: 'I like that better' before singing along. In another session, a slow 'sad' tune found Aileen glancing at her watch (an indication of boredom). Edward tapped his foot along with the quicker-paced tunes, but it was the slower-paced tunes that evoked exclamations of 'yeah!' and 'that's it!' - prompting the fieldnote observation that, '... Edward seemed to really be transported during the slower suave tunes'. Edine tapped and nodded along with the faster-paced music; however, the slower-paced music prompted blissful expressions as her eyes closed while swaying gently. Hazel identified several slower-paced tunes as favourites, while at the same time stating that she didn't like listening to 'sad' tunes. Hazel's carer later observed: '. . . when it was a slower song ... I felt that Hazel would sit with her eyes shut, but when it was a cheerier song then ... she'd pep up a wee bit' (carer). This observation illustrates the subjectivity that observers are prone to. Hazel's less overt responses to 'slower songs' didn't necessarily mean she was not asas involved with the music. 
These examples underscore the importance of each person providing music to be knowledgeable in recognising and matching the mood and energy of each listener in order to successfully facilitate each listener's engagement with the music being played.

\section{Music genre}

The genre of the music being played can also greatly affect the experience of each listener, illustrated in the excerpts below.

Whenever Aileen heard Celtic tunes, or lively hymns she would nod her head and sing along. Edward expressed his preference for 1940s ballroom dance music by whistling, tapping his foot, and remaining attentive whenever this genere of music was played, however whenever Scottish music or hymns were played (upon the insistence of his daughter), he appeared distracted. Robert loved all music, but whenever Scottish music was played, he immediately began nodding his head and tapping his/hands along with the music - and generally interacted more as well. Cait particularly brightened whenever she heard Scottish tunes and hymns; laughingly exclaiming after hearing a Scottish tune: 'Something rousing about Scottish music!'

These examples illustrate how a listener's affinity with not only specific tunes, but whole music genres may considerablely impact their experience.

\section{Individualised music: Identification}

Familiar music is recognised as a powerful tool for eliciting memories and supporting reminiscence for people living with dementia (Gerdner \& Schoenfelder, 2010; Janata, 2012; Sakamoto, Ando, \& Tsutou, 2013). This study uncovered an additional beneficial aspect of listening to familiar music for some participants living with dementia: identification.

Identifying the music played significantly impacted on each resident's experience. Some residents had difficulty identifying the familiar music they were listening to. Some residents approached identifying each tune as an enjoyable challenge; listening intently with furrowed brow, until suddenly bursting into a broad smile signifying successful identification of the tune. While some residents disengaged when unable to identify the music, other residents enjoyed the music regardless. For example, Betsie expressed considerable pleasure and pride at correctly identifying and knowing the words to virtually every tune. At the end of their first music intervention, her nephew Gavin noted: 'She's [Betsie] enjoyed it .. . amazed at the memory she's got for the ... it seems odd ... but eh, it's, the memory is a queer thing isn't it ... it's been years since she's ever heard these tunes anyway ... well for the first two three notes or strokes of the fiddle she's joining in ...' Upon correctly identifying a tune, Edine would raise her eyebrows, widen her eyes, burst into a broad grin, nod her head, and begin swaying or tapping along with unbridled delight. During one session, as soon as she heard, 'You are my sunshine', she shook her head, grinned broadly, and exclaimed; 'That's it!' Bonnie usually looked towards her daughter Nessa to supply names of tunes as they began. At the start of one tune Bonnie said to Nessa, 'I don't know what this is she's playing' - upon hearing the name, she responded, 'Oh ay [yes].' After singing along with, 'Loch Lomond', Bonnie said, 'I ken [know] that one.' During her exit-interview, Nessa commented:

'... I think it's the sort of thing that obviously works because you saw how suddenly she [Bonnie] would perk-up and go, "ooh"! And realise, recognise the tunes from years ago, and 
so it does definitely stimulate .. . and you see sometimes when her foot would go or her arms would go, that she understood what was going on. Em, and that she was enjoying it because it jogged her memory for ... I think it definitely worked ...'

These excerpts illustrate the positive impact that correctly identifying a familiar tune had for most residents, and thus how this aspect of listening to familiar music likely contributed to an internalised 'haven'.

\section{Embodied memories and time travel}

A vast amount of knowledge and memories is stored not only within our brains, but also within our bodies (Coaten \& Newman-Bluestein, 2013; Kontos, 2012; Kontos \& Martin, 2013), which is retained even in people with advanced dementia (Dekkers, 2011; Kontos, 2012). This study suggests that familiar music can access these embodied memories.

After one session, Maggie spoke at length about growing-up the youngest in a large coalmining family and losing her closest brother during World War II (WWII). Various familiar tunes also evoked memories of her late husband; who she reportedly rarely spoke about. For example, upon hearing, 'Dashing white sergeant', Maggie smiled broadly, began moving with the music and exclaimed, 'this is like a dream!' before putting her hands to her eyes and crying during the rest of this tune:

Jean to Maggie: You okay? [Maggie nodding and smiling slightly]

Author: What are you thinking about Maggie?

Jean: Are you sad? ... Emotional?

Maggie: [nodded] Emotional dear.

Maggie: Just thinking about my husband, and $\ldots$ things we did ...

Hearing 'The white cliffs of Dover', Bonnie began rhythmically kicking-up her legs; Bonnie was in the Auxiliary Territorial Service (ATS) during WWII, so this popular WWII tune likely triggered embodied memories associated with her activities during that time of her life. Hearing 'Scotland the brave', Bonnie began making highland-dance type gestures:

Author to Bonnie: Were you doing a little dancing to that one?

Bonnie: Ay!

Author: Did you do that when you were little ...?

Bonnie: Oh yes! Yes!

This well-known Scottish tune seemingly evoked embodied memories for Bonnie of highland dancing as a little girl.

Traditional Scottish dance tunes were so ingrained in Robert that he frequently 'danced' along with complex footwork - despite by all appearances being asleep! The capacity of music to arouse embodied memories is captured by the observations of this care home manager:

'It [music] was bringing out the person that they were, and still are. But because through dementia, they're locked in a place, and it's always a place where we can't access. But through that music, it touched their hearts and their souls. And in doing that, it brought them out to that 
place they once were. So that they remembered this music, and what it meant to them. And that gave them meaning and purpose in their lives again.'

These excerpts show music's ability to directly connect with embodied memories; thus 'transporting' listeners out of their reality - perhaps into a more enjoyable 'haven'. It also illustrates the importance of providing each listener with familiar 'touchstones' related to their cultural identity (Brooker, 2007).

\section{Discussion: Haven}

A key finding from this study was that external elements of the intervention (e.g. repeated format, people present, familiar setting), coupled with characteristics of the music played (e.g. tempo, mood, live or pre-recorded, genre, personal meaning) evoked an internalised experience of 'haven' for participants.

The beneficial impacts that modifying physical environments (e.g. signage, colours, tex-tures, etc.) can have for people living with dementia is now widely accepted (Davis, Byers, Nay, \& Koch, 2009; Marshall, 2012). However, these types of alterations are often unfea-sible due to financial and other practical constraints. The findings from this study suggest that the skilled use of music can 'transport' listeners - including those with advanced demen-tia, out of their current physical and emotional reality into an internalised 'haven' - at substantially less cost. Additionally, when two people share this listening experience, parity, memories, emotions, and (re)connections can flourish within this 'haven'.

The repeated format, reintroducing myself and the intervention, re-obtaining consent and reminding each resident that $\mathrm{s} /$ he was in charge - may have helped prepare resident participants to be more receptive to the music. The nature of these repeated interventions also provided residents with the nurturing experience of being the centre of attention, and of having their wishes (whenever possible) immediately acknowledged and acted-upon, which was likely unusual in their present living situation. Consequently, residents were able to experience the satisfaction of two of Kitwood's (1997) stated basic human needs; 'inclusion', and 'comfort', before the music even began - facilitating the music's ability to fulfil Kitwood's (1997) basic human needs of 'identity' (recognising familiar music and relating to themselves in their history); 'occupation' (engaged listening and interacting with the music and all who were present ); and 'attachment' (connecting to their dyad partner in their shared experience) more successfully; thus engendering a 'haven' for listeners.

The length of each session varied, being predicated on each resident's responses. A res-ident who, after being wholly engaged, alert and energetic during an extended (near or over an hour) music intervention, can be said to have experienced 'Flow' (Csikszentmihalyi, 1997); or 'IME' (Sch@fer et al., 2014). Responses such as these are additional indications that these interventions were successful at 'transporting' a participant into an absorbing, fulfilling, and enjoyable 'haven.'

Connecting with others is a basic human need which never diminishes, but as we grow older, cognitive and physical changes may challenge our ability to connect (Froggatt et al., 2009). The residents participating in this study represent a growing population of people less likely to benefit from group activities generally offered, however these findings support prior research showing that when visitors share an activity with aa care home resident, their interactions are enhanced (Nolan et al., 2003). Indeed carers and staff were delighted and surprised by the level of engagement/enjoyment they observed. That the residents benefited 
from increased visits and attention throughout this study should not be ignored. This study's findings suggest that it was the external elements of these music interventions (i.e. a repeated format in the same setting with the same people present, etc.), combined with characteristics of the music played (i.e. tempo, mood, genre, live/pre-recorded, recognisabil-ity, meaning, etc.) that cultivated an internalised 'haven' wherein each of Kitwood's (1997) basic human needs (love, comfort, identity, occupation, inclusion, and attachment) were fulfilled within each participant.

\section{Barriers and limitations}

It is important to discuss the barriers/limitations experienced in this study towards inform-ing future research and practice within this under-researched area. Many of this study's limitations can be attributed to individual circumstances:

- Pre-recorded music did not 'work' for several participants.

- Some carers found the music interventions enjoyable and relaxing; others found them somewhat taxing due to keeping watch over their dyad partner.

- Familiar music sometimes evoked sad or even unpleasant memories; while sadness is not a 'negative' response, whomever is 'administering' music must be trained in understand-ing nonverbal communication - and quickly stopping/changing music if it is arousing upset or agitation in a listener.

- While guessing the name of familiar music evoked enjoyment for some residents, others remained disengaged and even tense until the tune was identified; again demonstrating the importance for the music 'administrator' to be trained in recognising and reacting to nonverbal cues.

- The genre of the music played can greatly impact a listener's experience; again, understanding nonverbal communication will aid the music 'administrator' in responding to each listener's reactions - which will likely be quite changeable.

- The level of openness to creative arts being introduced within a care home generally depends on the manager's understanding and attitudes, coupled with comprehensive communication with staff and family. Therefore, careful consideration towards most effectively disseminating relevant information to managers, staff, and families is critical for the success of future related projects.

\section{Conclusion}

This paper provides insight into the impact that receptively listening to personalised music in the company of a significant other can have for all involved, regardless of their physical/cognitive frailties. The culmination of these findings is that, combined external conditions (e.g. session format, people present, provision of high quality music chosen and provided by someone appropriately trained, etc.), can help 'transport' listeners into an internalised 'haven' wherein Kitwood's basic human needs for occupation (with the music); inclusion (with people present); identity (through significant music); comfort (through significant music, familiar setting, familiar people present); and attachment (with significant music and others present) can be fulfilled. These findings are particularly pertinent for residents who, due to cognitive/physical frailties may not benefit or be able to attend group activities - 
as well as for their families and friends who may, for similar reasons, have lost a sense of connectedness

Future research is needed both to replicate this study's findings, and to explore the relative impacts of unfamiliar music/music genres. The ethical morass related to research with people deemed unable to provide direct informed consent necessitates ongoing consid-eration and debate - and must include input from people who are living with dementia. While this study's findings support prior research regarding the benefits of music, this study added knowledge and understanding by drilling down into what it was about the music and interventions that 'worked' for whom and why (Pawson \& Tilley, 1997). Further research is warrented as to how best to harness music's potential for enriching social contact between people with advanced dementia and who are physically frail with those who care for and support them. Allocation of funding for training musicians and staff in nonverbal commu-nication, dementia, entrainment, music genres, etc. could provide more of these intimate music listening opportunities, particularly for residents who are unable to attend/engage in general care home activities. This would be money well spent.

\section{Acknowledgements}

Special thank you to Professor Alison Bowes and Dr Alison Dawson for their support, and to all the participants and care home staff involved in this project.

\section{Declaration of conflicting interests}

The author(s) declared no potential conflicts of interest with respect to the research, authorship, and/or publication of this article.

\section{Funding}

The author(s) received no financial support for the research, authorship, and/or publication of this article.

Notes

1. At the time of this study, the majority of people living in Scottish care homes may not have an official diagnosis of dementia (Scotland's National Dementia Strategy, 2013); thus, I sought the opinion of care home managers ( Sixsmith \& Gibson, 2007) regarding each prospective resident participant's dementia status. Ethical approval required each participant be able to provide direct informed consent.

2. To clarify, this prediction of proximity to dying was due to physical ailments or co-morbidities, not due to a resident's level of dementia, as each resident participant was required to be able to provide witnessed direct informed consent.

3. The original 'surprise question' asks practitioners 'Would you be surprised if the patient were to die within one year?' (Moss et al., 2008; Thomas, 2010). 


\section{References}

Allan, K. (2006). Environmental and team approaches to communication in the dementias. In K. Bryan \& J. Maxim (Eds), Communication disability in the dementias (pp. 184-200). London, UK: Whurr Publishers Ltd.

Aragon, D., Farris, C. \& Byers, J. F. (2001). The effects of harp music in vascular and thoracic surgical patients, Alternative Therapies in Health and Medicine, 8(5), 52-60.

Bartlett, R., \& O'Connor, D. (2007). From personhood to citizenship: Broadening the lens for dementia practice and research. Journal of Aging Studies, 21(2), 107-118.

Birch, D., \& Draper, J. (2008). A critical literature review exploring the challenges of delivering effective palliative care to older people with dementia. Journal of Clinical Nursing,

17(9), 1144-1163.

Black, B. P., \& Penrose-Thompson, P. (2012). Music as a therapeutic resource in end-of-life care. Journal of Hospice \& Palliative Nursing, 14(2), 118-125.

Bradt, J., \& Dileo, C. (2010). Music therapy for end-of-life care. Cochrane Database of Systematic Reviews, 1, .

Brooker, D. (2007). Person-centred dementia care: Making services better. London: Jessica Kingsley Publishers.

Brooker, D., Fontaine, L., De, J., Vries, K., Porter, T., \& Surr, C. (2011). How can I tell you what's going on here? The Development of PIECE-dem: An observational framework to bring to light the perspective of residents with advanced dementia living in care homes. Worcester: Association for Dementia Studies.

Calveley, J. (2012). Including adults with intellectual disabilities who lack capacity to consent in research. Nursing Ethics, 19(4), 558-567.

Clair, A. A. (2002). The effects of music therapy on engagement in family caregiver and care receiver couples with dementia. American Journal of Alzheimer's Disease and Other Dementias,

17(5), 286-290.

Coaten, R., \& Newman-Bluestein, D. (2013). Embodiment and dementia - Dance movement psychotherapists respond. Dementia, 12(6), 677-681.

Craig, P., Dieppe, P., Macintyre, S., Michie, S., Nazareth, I., \& Petticrew, M. (2006). Developing and evaluating complex interventions: The New Guidance. Medical Research Council, London.

Csikszentmihalyi, M. (1997). Flow and the psychology of discovery and invention (2nd ed.). New York, NY: Harper Perennial.

Cuddy, L. L., \& Duffin, J. (2005). Music, memory, and Alzheimer's disease: Is memory recognition spared in dementia, and how can it be assessed?. Medical Hypotheses, 64, 229-235.

Davis, S., Byers, S., Nay, R., \& Koch, S. (2009). Guiding design of dementia friendly environments in residential care settings: Considering the living experiences. Dementia, 8(2), 185-203.

Dekkers, W. (2011). Dwelling, house and home: Towards a home-led perspective on dementia care. Medicine, Health Care and Philosophy, 14(3), 291-300.

Dewing, J. (2009). Making it work: A model for research and development in care homes. I. In S. M. Davies, K. Froggatt \& J. Meyer (Eds), Understanding care homes: A research and development perspective (pp. 222-224). London: Jessica Kingsley Publishers.

Diaz, F. M. (2013). Mindfulness, attention, and flow during music listening: An empirical investigation. Psychology of Music, 41(1), 42-58.

English Oxford Living Dictionaries. (2018). Retrieved July 29, 2018, from https://en.oxforddiction aries.com/definition/haven

Fachner, J. (2007). Wanderer between worlds - Anthropological perspectives on healing rituals and music. Music Therapy Today, 8(2), 166-195.

Froggatt, K., Davies, S., \& Meyer, J. (2009). Research and development in care homes: Setting the scene,

A Research and Development Perspective (pp. 9-22). London: Jessica Kingsley Publishers. Garabedian, C.

E. (2014). 'I'D RATHER HAVE MUSIC!': The effects of live and recorded music for people with dementia living in care homes, and their carers. Stirling: University of Stirling. 
Gerdner, L. A. (2000). Effects of individualized versus classical "relaxation" music on the frequency of agitation in elderly persons with Alzheimer's disease and related disorders, International

Psychogeriatrics, 12(01), 49-65.

Gerdner, L. A., \& Schoenfelder, D. P. (2010). Evidence-based guideline, Individualized music for elders with dementia. Journal of Gerontological Nursing, 36(6), 7-15.

G6tell, E., Brown, S., \& Ekman, S. L. (2009). The influence of caregiver singing and background music on vocally expressed emotions and moods in dementia care. International Journal of Nursing Studies, 46(4), 422-430.

Hammersley, M., \& Atkinson, P. (2007). Ethnography: Principles in practice (3rd ed.). London / New York, NY: Routledge.

Hargie, O., \& Dickson, D. (2006). Skilled interpersonal communication: Research, theory and practice (4th ed.). East Sussex / New York, NY: Routledge.

Heiderscheit, A., \& Madson, A. (2015). Use of the iso principle as a central method in mood management: A music psychotherapy clinical case study. Music Therapy Perspectives, 33(1), 45-52.

Hennings, J., Froggatt, K., \& Keady, J. (2010). Approaching the end of life and dying with dementia in care homes: The accounts of family carers. Reviews in Clinical Gerontology, 20(2). 114-127.

Hilliard, R. E. (2000). The use of music therapy in meeting the multidimensional needs of hospice patients and families. Journal of Palliative Care, 17(3), 161-166.

Hogan, B. E. (2003). Soul music in the twilight years: Music therapy and the dying process. Topics in Geriatric Rehabilitation, 19(4), 275-281.

Hubbard, G., Cook, A., Tester, S., \& Downs, M. (2002). Beyond words: Older people with dementia using and interpreting nonverbal behaviour. Journal of Aging Studies, 16(2), 155-167.

Hubbard, G., Downs, M. G., \& Tester, S. (2003). Including older people with dementia in research: Challenges and strategies. Aging \& Mental Health, 7(5), 351-362.

Hughes, J. C. (2013). Y'feel me?' How do we understand the person with dementia? Dementia, 12(3), 348-358.

Killick, J., \& Allan, K. (2001). Communication and the care of people with dementia. Buckingham / Philadelphia, PA: Open University Press.

Kitwood, T. (1997). The experience of dementia. Aging \& Mental Health, 1(1), 13-22.

Khalfa, S., Roy, M., Rainville, P., Dalla Bella, S. \& Peretz, I. (2008). Role of tempo entrainment in psychophysiological differentiation of happy and sad music?, International Journal of

Psychophysiology, 68(1), 17-26.

Kontos, P. C. (2012). Rethinking sociability in long-term care: An embodied dimension of selfhood. Dementia, 11(3), 329-346.

Kontos, P., \& Martin, W. (2013). Embodiment and dementia: Exploring critical narratives of selfhood, surveillance, and dementia care. Dementia, 12(3), 288-302.

Marshall, M. (2012). Dementia-friendly design guidance for hospital wards. Journal of Dementia Care, 20(4), 26-28.

Martin, G. W., \& Younger, D. (2000). Anti oppressive practice: A route to the empowerment of people with dementia through communication and choice. Journal of Psychiatric and Mental Health Nursing, 7(1), 59-67.

Mauthner, N., \& Doucet, A. (1998). Reflections on a voice-centred relational method. In J. Ribbens \& R. Edwards (Eds), Feminist dilemmas in qualitative research: Public knowledge and private lives (pp. 119-146). London: Sage Publications Ltd.

Moss, A. H., Ganjoo, J., Sharma, S., Gansor, J., Senft, S., Weaner, B., \& Schmidt, R. (2008). Utility of the "surprise" question to identify dialysis patients with high mortality. Clinical Journal of the American Society of Nephrology, 3(5), 1379-1384.

Murphy, J., Gray, C. M., \& Cox, S. (2007). Communication and dementia: How talking mats can help people with dementia to express themselves. Project Report, Joseph Rowntree Foundation. National

Gold Standards Framework Centre (2011). The Gold Standards Framework. 
National Institute for Health and Care Excellence. (2018). Donepezil, galantamine, rivastigmine and memantine for the treatment of Alzheimer's disease. London: NICE. Retrieved July 4, 2018, from https://www.nice.org.uk/Guidance/TA217

Nolan, M., Lundh, U., Keady, J., \& Grant, G. (2003). New directions for partnerships: Relationshipcentred care. In M. Nolan, U. Lundh, G. Grant \& J. Keady (Eds), Partnerships in family care (pp. 257291). Philadelphia, PA: McGraw-Hill International.

Nolan, M., Ryan, T., Enderby, P., \& Reid, D. (2002). Towards a more inclusive vision of dementia care practice and research. Dementia, 1(2), 193-211.

Pawson, R., Greenhalgh, T., Harvey, G., \& Walshe, K. (2005). Realist review - A new method of systematic review designed for complex policy interventions. Journal of Health Services Research \&

Policy, 10(suppl 1), 21-34.

Pawson, R., \& Tilley, N. (1997). Realistic evaluation (4th ed.). London: Sage.

Prince, M. J. (2015). World Alzheimer Report 2015: The global impact of dementia: an analysis of prevalence, incidence, cost and trends. Alzheimer's Disease International.

Sakamoto, M., Ando, H., \& Tsutou, A. (2013). Comparing the effects of different individualized music interventions for elderly individuals with severe dementia. International Psychogeriatrics, 25(5), 775-784. Sch

afer, T., Smukalla, M., \& Oelker, S. A. (2014). How music changes our lives: A qualitative study of the long-term effects of intense musical experiences. Psychology of Music, 42(4), 525-544. Scottish Government (2013). Scotland's National Dementia Strategy, 2013-2016.

Sixsmith, A., \& Gibson, G. (2007). Music and the wellbeing of people with dementia, Ageing and Society, 27(01), 127-145.

Thomas, K. (2010). The GSF prognostic indicator guidance. End of Life Care, 4(1), 62-64.

Van der Geer, E. R., Vink, A. C., Schols, J. M. G. A., \& Slaets, J. P. J. (2009). Music in the nursing

home: Hitting the right note! The provision of music to dementia patients with verbal and vocal

agitation in Dutch nursing homes. International Psychogeriatrics, 21(01), 86-93.

Ward, R., Vass, A. A., Aggarwal, N., Garfield, C., \& Cybyk, B. (2008). A different story: Exploring

patterns of communication in residential dementia care. Ageing and Society, 28(5), 629-651. Wilson, C.

B. (2009). Developing community in care homes through a relationship-centred approach.

Health \& Social Care in the Community, 17(2), 177-186.

Claire E Garabedian is a postdoctoral researcher and lecturer at the Association for Dementia Studies, University of Worcester. Claire is a professional cellist specialising in historical performance, a Certified Music Practitioner through the US based Music for Healing \& Transistion Program (MHTP). Claire's unique combination of qualifications provides for an understanding of both practice and research aspects regarding the rewards and challenges involved in working within these populations as well as within the creative art practitioner diaspora. Claire has been invited to present and join round-table panels regarding her research work in the UK, Europe and the USA, and has been a guest on BBC radio 4 (Saturday Live) and at the Hay Literature Festival. She has recently become a member of the Music For Life musician's team at the Wigmore Hall, and of HealthPitch (healthpitch.org) exploring all facits of music for health and wellbeing.

Fiona Kelly is a lecturer in the Nursing Division and a member of the Person-centred Practice Research Centre at Queen Margaret University. Fiona has worked with people with dementia in a practice and research capacity for the past 20 years: working as a nurse in a care home and pursuing her academic career as a lecturer in dementia. Her philosophical and research interests include human rights, enduring selfhood in dementia, end-of-life care, dementia friendly design, assistive technology, cultures of care and hearing the views and opinions of people with dementia and those who support them. 